\title{
Participación y escolarización de la política: Reflexiones sobre lo político en la escuela
}

\author{
Participation and schooling politics: \\ Reflections over politics in school
}

\author{
Marina Larrondo ${ }^{1}$ \\ mlarrondo@udesa.edu.ar
}

\begin{abstract}
Resumen
En este artículo proponemos una discusión conceptual para el abordaje del vínculo entre jóvenes, escuela y política; centrando la mirada en las prácticas participativas de los estudiantes en la escuelas secundarias y las condiciones de politización de las mismas. La perspectiva propuesta integra conceptos provenientes de la teoría política y la sociología de la educación, desde donde discutimos la distinción entre la política y lo político; participación y política; concibiendo a la escuela como una institución específica. Planteamos una hipótesis interpretativa acerca de la "escolarización de la política" que surge del análisis de la compleja relación entre dos mundos constitutivamente en tensión: el de la política y el de la escuela secundaria. Por último, nos preguntamos si todas las formas de participación y politización tienen las mismas potencialidades para describir e interpretar empíricamente este objeto de estudio, pero también para la protección y/o la ampliación de derechos de los jóvenes
\end{abstract}

Palabras clave

Participación, política, escuela secundaria, dispositivos, juventudes.

Forma sugerida de citar: Larrondo, Marina (2017). Participación y escolarización de la política: Reflexiones sobre lo político en la escuela. Universitas, $X V(26)$, pp. $109-134$

1 Investigadora Asistente del Consejo Nacional de Investigaciones Científicas y Técnicas-CONICET, Argentina, con sede de trabajo en el Centro de Investigaciones Sociales-IDES/CONICET. Este trabajo se origina en hallazgos y reflexiones producto de la investigación doctoral financiada por una beca doctoral interna tipo II y postdoctoral interna del CONICET en los años 2011 a 2013 y 2016 a 2017 respectivamente. 


\begin{abstract}
In the following article we intend to reflect and discuss the conceptual link between youth, school and politics. We will focus on the student's participative practices and the political conditions in middle schools. Our perspective integrates concepts which originate in the political theory and sociology of education. The latter will be the starting point from where we will discuss the difference between politics and political in the school context, while we consider the school as a specific institution. We set an interpretative hypothesis about the "scholarisation of politics" based on the complex relationship between two worlds in tension: the political and the middle school worlds. Lastly, we ask ourselves if every form of participation and politization has the same potential to describe and empirically interpret the aim of this study, but also for the protection and broadening of youth rights.
\end{abstract}

\title{
Keywords
}

Participation, politics, middle school, apparatus, youth .

\section{Introducción}

El objetivo de este artículo es presentar un conjunto de hipótesis teóricas para interpretar la emergencia y desarrollo de lo político en la escuela secundaria y ahondar en sus complejas interacciones y efectos. Entendemos a la escuela como institución que, a partir de una determinada configuración socio-histórica, distribuye conocimientos y regulaciones morales que incluyen la dimensión política, y con ello, se conforma como un particular espacio de socialización y práctica política de los y las jóvenes².

La lectura conceptual que proponemos surge de una sistematización a partir de un conjunto de hallazgos empíricos que, como tales, se originaron en

2 Cabe aclarar que aquí no avanzaremos sobre el movimiento estudiantil en sí sino sobre las prácticas que se dan al interior de las escuelas, aunque obviamente estas se ven afectadas y sobredeterminadas por el movimiento estudiantil. No obstante, creemos que conservan su independencia y la comprensión de su dinámica también contribuye a entender cómo se dan ciertas dinámicas con las organizaciones del movimiento estudiantil. Para el caso argentino, se puede consultar Enrique (2011), Larrondo (2014), Núñez (2013) y Manzano (2009). 
casos concretos ${ }^{3}$. No obstante, creemos que nuestras lecturas pueden resultar fructíferas -en tanto tienen cierto grado de generalidad-para discutir y o abordar conceptualmente este objeto de estudio en otros contextos y escuelas.

El trabajo se organiza en torno a tres grandes argumentos. En primer lugar, sostendremos que la diversidad de espacios participativos en la escuela secundaria tienen un núcleo de formatos comunes y que en algunos de ellos emerge lo político mientras que en otros esto se ve obstaculizado. En segundo lugar, proponemos que la distinción entre la política y lo político permite hacer observable esta cuestión y sus efectos. En tercer lugar, creemos que existe un proceso de escolarización de la política que se visibiliza mediante la conceptualización de la escuela en tanto conjunto de dispositivos específicos que "fabrican" productos escolares, siendo la política escolar uno de ellos. Por último, mostraremos como este encuentro entre la escuela y lo político puede redundar en diferentes condiciones de posibilidad para el ejercicio de los derechos estudiantiles a través de la conformación de una voz propia y colectiva, y que ello se vincula -además- con características más amplias del ejercicio de la ciudadanía en la contemporaneidad.

\section{Propuestas y desafíos conceptuales: participación, participacionismo y política}

La escuela media es un ámbito donde existen múltiples dispositivos de participación por parte de los jóvenes: centros de estudiantes, club de jóvenes, grupos pastorales, asambleas, cuerpos de delegados, consejos de aula. En algunos países de América Latina existen los "personeros" o representantes estudiantiles que integran un consejo de escuela junto a autoridades y docentes. Algunos de estos dispositivos tienen funciones representativas legalmente reconocidas, otros no necesariamente o existen ambas instancias en una misma institución. Más allá de sus distintos nombres y funciones legales -o incluso informales-, en las escuelas es común encontrar dispositivos de participación juvenil que llevan adelante distintas actividades. En el caso de Argentina -por ejemplo-, los centros de estudiantes están reconocidos legalmente como instancias de participación y acción juvenil pero también de re-

3 Se trató de un trabajo de observación sistemática que incluyó no sólo considerar el funcionamiento de dispositivos escolares del presente en Argentina, sino también del pasado y de diversos países de la región (Larrondo, 2014; Núñez, 2013, entre otros). 
presentación de intereses estudiantiles. Existe una normativa nacional y varias normativas provinciales que establece su obligatoriedad y/o impulsan su conformación y regulan sus funciones. En la práctica, encontramos distintas situaciones: a-centros de estudiantes con larga tradición, donde la discusión política es tarea cotidiana a partir de una fuerte presencia militante; b-centros de estudiantes con un funcionamiento más esporádico que se activan en momentos de conflictividad educativa; c-escuelas donde no aparece un fuerte interés en participar por parte de los jóvenes y no se logra conformar el centro de estudiantes, o d-centros de estudiantes más centrados en actuar "dentro" de la escuela a partir de llevar adelante distintos emprendimientos (solidarios, culturales, de mejora escolar) pero sin "meterse en política" o "plantear conflictos"4. En estos últimos casos, la función representativa o más gremial aparece fuertemente desdibujada. Esta última característica no surge solamente desde los estudiantes y su "desconfianza a la política". Justamente, de todos los casos analizados, llaman particularmente la atención algunas lógicas de funcionamiento que se dan en este tipo de espacios, donde los adultos parecen colonizar y tener la capacidad de re direccionar la participación de los y las jóvenes hacia una que elimine cualquier huella de conflicto o autonomía en la conformación de demandas, identidades o intereses. Ello es frecuente de encontrar en las escuelas privadas (interesadas en desmarcarse de ciertas tradiciones "combativas" de la escuela pública), aunque no solamente. Podríamos decir que se trata de una estrategia consciente de ciertos adultos: los directivos convocan a la participación de los estudiantes pero intentando traducir la normativa a dispositivos ya existentes en sus escuelas, o bien, de imprimirles un carácter neutral y no representativo de "intereses estudiantiles" con el fin de desmarcarse del formato centros de estudiantes visualizados como problemáticos-. De este modo, se cumple con la normativa vigente a la vez que se distancian de potenciales fuentes de conflictividad. Como mencionamos, se produce un borramiento del propósito de "defender y representar derechos estudiantiles" por la de "proponer, participar y hacer" cosas "útiles" o "productivas" para la escuela.

Ahora bien, ¿qué sucede con los estudiantes? aquí es interesante tener en cuenta que los y las estudiantes traducen distintas posturas. En los centros de estudiantes (y sus diferentes tipos) no solamente participan los jóvenes

4 Para profundizar sobre estos distintos tipos de participación en las escuelas secundarias, ver Núñez (2013) y Larrondo (2014). 
que tienen militancia política, aunque suelen ser muy activos cuando están presentes. Asimismo, participa una parte importante de estudiantes que tienen extrañeza hacia cuestiones visualizadas como "políticas" y las connotan en sentido negativo. Dentro de este grupo, algunos jóvenes si defienden sus derechos en tanto estudiantes "sin meter la política en el medio" mientras que otros no llegan a verse a sí mismos como sujetos de derecho, desconocen tanto las leyes y normativas que los habilitan como el margen de cuestiones en las que pueden intervenir y demandar de modo legítimo.

Como adelantáramos, esta dinámica redunda en la formación de organizaciones estudiantiles que se centran puramente en lo participativo-cooperativo. Esto implica que en la práctica, poco tiene que ver con organizaciones que representan intereses estudiantiles y defienden derechos legalmente consagrados (lo cual no es lo mismo que proponer actividades, llevar adelante iniciativas o pedir concesiones a los adultos). Un ejemplo concreto de los efectos de esta dinámica pudo encontrarse en el caso de una de las escuelas religiosas analizadas: la organización estudiantil conformada adoptó la mayoría de los rasgos de los grupos de pastoral juvenil que ya funcionaban en el colegio. Su tarea fue continuar realizando acciones solidarias y en beneficio de la convivencia escolar, pero agregando la idea de que ello también era "decidir democráticamente" y se añadía la posibilidad de hacer propuestas de interés de los alumnos (uso de espacios, concesiones en el uniforme o del uso del cabello o presentación personal) que después los directivos concedian o no.

Más concretamente: en algunas escuelas los estudiantes reclaman a partir de apelar a normativas el cumplimiento (o ampliación o interpretación) de derechos, mientras que en otras estos derechos y cuestiones están enlazadas a cosmovisiones políticas más amplias y en un último grupo de escuelas los estudiantes no llegan a conformar un nosotros (estudiantil) basado en una perspectiva colectiva y con algún grado de consciencia de sus derechos o inserción en la escuela y el sistema educativo.

Hasta aquí las diferencias. Ahora bien, más allá de que las instancias de participación lleguen a conformarse bajo estas distintas modalidades, se enmarquen en un discurso de derechos y eventualmente utilicen la protesta como herramienta o no, tienen un aspecto en común que dice mucho: todas, de modo regular, planifican y llevan a cabo un conjunto de actividades juveniles participativas. Se trata de un repertorio de actividades estudiantiles estables y cotidianas. Mediante la observación, hemos constatado que tienen 
un conjunto de características específicas. Son extracurriculares, tienen cierto grado de autonomía de las autoridades, se llevan a cabo por estudiantes en espacios separados del aula y suponen un obrar en común.

Estas actividades permiten vehiculizar varias cosas: 1. El obrar mancomunado; 2. La conformación de un espacio de sociabilidad juvenil; 3. La expresión de la voz de los jóvenes; 4. La posibilidad de llevar a la escuela temas, debates, discusiones que expresan intereses por diversas cuestiones "públicas", permitiendo - cuando se dan ciertas condiciones- direccionarlas de acuerdo a ideologías políticas más amplias (por ejemplo, en los casos en que las charlas o jornadas de reflexión tocan ciertos temas y no otros); o bien, a enmarcar sus inquietudes en términos de derechos. No sólo permiten el "hacer en común" sino que tienen la potencialidad de politizar la participación. Estas instancias, además, se fueron configurando como parte de la vida institucional de las escuelas, como actividades de los estudiantes secundarios. Generalmente los estudiantes o docentes mencionan que este obrar en común tiene un sentido político, democrático, o es llamado "otro modo de hacer política”. Así, significantes como política, democracia, aprendizaje y participación genuina, en oposición a otra política "contaminada" también suelen articular los sentidos que se le dan a estos dispositivos.

Llegados a este punto, sostendremos que, no obstante, esto no siempre está vinculado con la emergencia de lo político en el ámbito escolar, y que desarrollar esta tensión conceptual y empírica es altamente relevante tanto para la investigación de las prácticas políticas como para las intervenciones con los y las jóvenes. Creemos que la presencia de múltiples formas de participación estudiantil y sus sentidos nos colocan frente a una cuestión sinuosa: los límites entre lo político y lo asociativo, los límites entre "lo político", "la política", y un más allá que podríamos llamar cooperativo o participativo. Esta cuestión es muy relevante cuando el escenario es la escuela. ¿Por qué? Porque la institución escolar es, en sí misma, espacio de permanente actividad "participativa" de los jóvenes, dado que es un eje central de numerosas prácticas pedagógicas. Asimismo, que los estudiantes se involucren y participen se ha conformado como parte de la gramática escolar (Tyack y Cuban, 2004) de la escuela secundaria.

No puede olvidarse que la escuela media es una institución con un sentido específico: la transmisión de conocimientos y valores en sistemas organizados (sistemas educativos) que contribuyen a la producción y reproducción de una determinada formación social. Para ello, crea determinados sujetos a 
partir de un discurso propio: el discurso pedagógico (Bernstein, 2001). Esto no es un dato contextual: la escuela, como característica fundante, es espacio de permanente actividad participativa y cooperativa de los jóvenes. El oficio de alumno (Perrenoud, 2006) de las pedagogías activas -fuertemente presente en la escuela contemporánea- se caracteriza por promover permanentemente el trabajo participativo y colaborativo, siendo ello un rasgo de la enseñanza y desde allí parte del rol exigido a los estudiantes en muchas escuelas. Por esto mismo, "la participación en la escuela" tiene múltiples orígenes y sentidos, y puede estar o no vinculada a la emergencia de lo político. Con todo esto, proponemos que las distintas dinámicas y modalidades de agrupamiento pueden leerse en términos de conformación de participacionismo o ir hacia una dinámica donde se conforma lo político dentro del espacio escolar.

Estas lógicas participativas no se agotan en la escuela, sino que también remiten a otro tipo de interrogantes más amplios sobre la gubernamentalidad, la democracia, la participación ciudadana en general y las transformaciones del ejercicio de la ciudadanía (Rosanvallón, 2008, entre otros) en nuestras sociedades. Esto se puede apreciar en el hecho de que la participación aparece como un concepto central en numerosas políticas públicas destinadas a jóvenes (Krauskopff, 2002; Vázquez, 2015), pero también a la ciudadanía más amplia (Annunziata, 2012). Algunos trabajos, incluso, son muy críticos con estos dispositivos participativos, enfatizando la pérdida del referente universal que comporta la política en detrimento del ámbito local y la proximidad (Annunziata, 2012) lo cual no permite plantear los problemas propios (del grupo particular) en términos de mirada de conjunto. Sobre ello avanzaremos en la sección siguiente.

\section{Lo político y sus fronteras: ¿Una distinción necesaria?}

Sabemos que las y los jóvenes participan en los asuntos públicos, hacen oír su voz y construyen colectivos muchas veces por fuera de los canales institucionalizados de la política e inclusive de los propios movimientos sociales. Lo hacen también a partir de múltiples intereses y demandas, y en ocasiones allí reside su novedad. La política por fuera de los espacios tradicionales de las democracias representativas -hecho que ya no es novedosoabarca también a las generaciones adultas: como sostiene Lechner (2000), 
uno de los rasgos de la participación política en contemporaneidad es el hecho de que esta "desborda el marco institucional" y las personas tienden a vincularse con lo político desde la vida cotidiana, sugiriendo que existe una “ciudadanización de la política". En una dirección similar, la categoría de "politicidad"5 entiende que "política" y "sociabilidad" van juntas y ello se visibiliza a través de la observación de colectivos y actores concretos, en una compleja trama de lazos que "necesita ser descripto en cada coyuntura, en cada lugar, para cada grupo social, y es en el conflicto ${ }^{6}$ que se lo define" (Merklen, 2005, pp. 18-19).

Así, la politicidad refleja diversidad, es decir, "no sólo la identidad y la cultura política de un colectivo o de un individuo sino también la totalidad de las prácticas a través de las cuales cada uno salta a la palestra a batirse por sus intereses y al espacio público para defender una concepción del bien común" (Merklen, 2005, pp. 18-19). Esta categoría acentúa no sólo la importancia de la vida en común y de la experiencia cotidiana, sino de lo público como definición colectiva y conflictiva. Aún en las infinitas posibilidades de manifestación y condiciones de producción, la politicidad comporta un aspecto irreductible: la conformación de intereses comunes, la conformación de algún tipo de antagonismo e identidad colectiva, la visibilidad pública, la construcción de un espacio público donde el bien común adquiere sentido, se define y se defiende, como un punto de vista.

Volviendo a las formas de participación dentro de la escuela antes presentadas y retomando lo anterior, nuestro primer punto argumentativo es que no toda instancia participativa de los estudiantes dentro de la escuela se conforma como instancia de participación política de los jóvenes. A su vez, todas las actividades participativas brindan un locus privilegiado para la emergencia de lo político, se constituyen en tanto posibilidad. Esta frontera entre lo participativo y lo político no es fija ni esencial, sino que es contingente, móvil y abierta al devenir de la acción colectiva. Y lo que resulte de ella tiene distintas consecuencias para los y las jóvenes.

Ahora bien, ¿qué entendemos como lo propio de lo político, como algo que puede emerger o quedar obturado? La noción de lo político y lo colectivo que utilizamos toma como punto de partida una visión agonística (Mar-

5 El uso de esta categoría para pensar las prácticas de los jóvenes en el nivel medio fue propuesto por Núñez (2013), para pensar el espacio escolar como configuración de prácticas políticas.

6 Itálicas propias. 
chart, 2009), la cual considera que lo político refiere a una dimensión de antagonismo -colectivo- constitutiva de las sociedades humanas (Mouffe, 2008), mientras que la política es entendida como "el conjunto de prácticas e instituciones a través de las cuales se crea un determinado orden, organizando la coexistencia humana en el contexto de la conflictividad derivada de lo político" (Mouffe, 2008, p. 16). La relación de antagonismo debe ser entendida no sólo como "presencia", sino también como una potencialidad. La emergencia de lo político es también central para la identidad colectiva, dado que es el antagonismo el que demarca a unos de otros, y por lo tanto funda un "nosotros", el cual será posible mientras identidades diferenciales puedan ser relativamente articuladas en torno a intereses que no preexisten, sino que son capaces de construirse en tanto tales en una dinámica colectiva; cuyo vehículo privilegiado es el discurso ${ }^{7}$.

De este modo, lo político es contingente e inestable, es una posibilidad siempre presente "y requiere desplazamientos y renegociaciones constantes entre los actores sociales" (Mouffe, 2008, p. 24). En cambio, el modo en que ese antagonismo se expresa remite en parte a la configuración de determinadas prácticas sobre la política. La expresión del antagonismo en las sociedades modernas puede redundar en distintas materializaciones. Algunas expresadas en un sistema de instituciones, por ejemplo, el propio de las democracias liberales; otras lo hacen por medio de otros formatos como los movimientos sociales. De este modo, se desprende de nuestro argumento que, más allá de los modos concretos en los que se organice lo político, la existencia del antagonismo/diferencia, al menos como potencialidad, es definitorio para comprender una acción colectiva, o "participativa" - por ejemplo, en el espacio escolar- como acción política.

Como se mencionó, la emergencia de lo político se da a través lo discursivo en tanto refiere a la construcción de sentido, los diferentes sentidos sobre la conformación de "problemas públicos", pero la potencialidad de esta multiplicidad no significa contingencia permanente ni revolución constante. Por el contrario, ese momento político suele dar lugar a modos concretos de gestión y participación, sostenidas desde dispositivos históricamente construidos. De allí se explica su grado de estabilidad, y de allí la importancia de la historia acumulada en la configuración de determinadas prácticas que tienden a reiterarse: "El lugar instituyente de esta irrupción de lo político no

7 En esta perspectiva, la noción de discurso es indisociable de la "práctica", la acción. 
supone, sin embargo, que todo lo que es lógicamente posible lo sea históricamente. No existe, en ese sentido, absoluta libertad: las prácticas sedimentadas (...) establecen un campo de posibilidades históricamente constreñido" (Retamozo Benítez, 2009). Como sostendremos más adelante, en esa ordenación y en esas formas históricamente posibles tiene mucho que ver en nuestro caso- la historia de la escuela como institución y sus dispositivos. Esto nos llama la atención sobre la importancia de observar cuidadosamente los repertorios de acción colectiva y las organizaciones juveniles y escolares a la hora de delimitar acerca de la novedad o continuidad de una forma de organización o de una práctica.

Otro aspecto fundamental de esta perspectiva de lo político -como mencionamos- refiere a la constitución de un nosotros y de una otredad. Podemos agregar un elemento más en este proceso: esta configuración de lo colectivo no se da en condiciones de igualdad, sino que existen lugares dominantes y otros subordinados, sólo algunos de ellos podrán constituirse subjetivamente y políticamente como tales. Al analizar prácticas políticas en la escuela, esta perspectiva orienta la indagación hacia las modalidades concretas de irrupción de lo político, pero también invita a prestar atención a los modos en que se instauran reglas de juego que posibilitan u obstaculizan su constitución y emergencia. Esto remite en última instancia a la posibilidad de conformación de identidades colectivas diferenciales en el espacio escolar: las reglas de juego en su interior muchas veces se traducen en formas "legítimas" de participar, "problemas" capaces de politizarse o no, disputas en torno a las cuestiones que podrán o no ser nombradas -y tratadas- como "públicas" en la escuela. El modo en que ello se resuelva en cada caso que observamos y estudiamos, nos permitirá analizar la emergencia de lo político.

De acuerdo con este recorrido, entonces, podemos realizar una primera distinción clave: aquella que se da entre prácticas políticas escolares y prácticas participativas escolares. Cabe aclarar que dicha distinción no pretende realizar una clasificación estanca y binaria, sino que establece fronteras conceptuales permeables y móviles para leer las prácticas en contexto. Concretamente, determinadas prácticas participativas al interior del espacio escolar podrán constituirse a partir de diversos grados de "politización" - tal como lo hemos definido- en el espacio escolar. En definitiva, si estamos de acuerdo con esta argumentación, las prácticas participativas de los jóvenes en las escuelas pueden ser consideradas en torno al desarrollo de lo político si es 
que ellas son capaces de articular (o más bien, "ir articulando") algún tipo de interés colectivo constituido como común, si son capaces de articular las conflictividades derivadas de las diferentes posiciones en un espacio institucional determinado, si suponen la posibilidad de conformación de identidades y otredades a partir de ello. Esta diferenciación plantea a lo político como una potencialidad, y a las fronteras entre lo participativo y lo político como unas que son dinámicas y permeables, aunque diferentes. En ese sentido, coincidimos con la propuesta de Bonvillani et al. (2008), quienes en un esfuerzo sistematizador sostienen que:

La politización es un potencial u horizonte constitutivo de cualquier vínculo social. Sin embargo, para atribuirle carácter político a un colectivo y a un sistema de prácticas sociales, consideramos que es preciso reconocer, al menos, cuatro aspectos: 1) que se produzca a partir de la organización colectiva; 2) que tenga un grado de visibilidad pública (ya sea de un sujeto, de una acción o de una demanda); 3) que reconozca un antagonista a partir del cual la organización adquiere el potencial político; 4) que se formule o una demanda o reclamo que, por lo dicho, adquiera un carácter público y contencioso (Bonvillani et al., 2008, p. 28).

En síntesis, entendemos que no toda acción participativa y colectiva en la escuela aún cuando los estudiantes actúen "en común" es política per se, y es más: que los actores digan y "hagan sentido" sobre ello no basta para comprenderla como tal. Sin duda, estos son datos clave y llevan a preguntas aún más complejas. Lo que proponemos a partir de lo presentado es construir un análisis de modo dinámico, centrarse en el devenir de la acción de los jóvenes en determinados formatos organizativos prestando particular atención al discurso, a la acción y a sus complejas articulaciones. La politización es así una posibilidad: podrá darse a partir de diversidad de prácticas y en distintos "grados", o bien podrá adquirir esta cualidad en determinados momentos y no en otros. Esto es relevante porque nos permite explicar cómo la presencia de determinados actores, como así también algunas formas organizativas y repertorios de acción, favorecen y posibilitan más el desarrollo de lo político, y, por el contrario, otras prácticas y estrategias intentarán despegarse de lo político en múltiples sentidos, incluso usando el calificativo de "político" como peyorativo. Por ejemplo, a partir del rechazo -y el intento de eliminar dentro de la escuela- aquello que se entiende como fuente de conflictividad y desde allí la formación de antagonismos, obstacu- 
lizando un proceso de construcción de identidades o intereses colectivos en tanto estudiantes.

En definitiva, en la escuela secundaria, las prácticas participativas de los jóvenes podrían analizarse como ubicaciones situacionales y temporales en distintos puntos de un continuum donde estas acciones pueden acercarse a formas de acción política -en los sentidos antes definidos-, o a formas asociativas y cooperativas cuyo carácter propiamente político es más borroso, desplazando el conflicto y el antagonismo, o bien, avocándose únicamente a una esfera de actividad relativa a la gestión de determinados asuntos comunes, cuyo carácter no se conforma necesariamente como "político", por ende, más alejado de lo universal, de la disputa por la definición de derechos y de la representación distinta y antagónica de unos intereses estudiantiles.

De este modo, es esperable que "centros de estudiantes", "cuerpos de delegados", "clubes estudiantiles" puedan politizarse en el devenir de sus acciones o a la inversa. Consideramos entonces que la distinción no ya entre política institucionalizada o política "no tradicional", o entre "gestión de la vida cotidiana" y "acción política" sino entre la emergencia de lo político y su imposibilidad resulta una diferenciación necesaria. Aún con diversos recaudos teóricos y metodológicos y con una vigilancia del propio rol del investigador a la hora de hablar acerca de las prácticas de los otros, mantenemos la vigencia de tal distinción con el fin de analizar las formas de actuar colectivamente al interior de la escuela.

De esta manera, llegamos a una primera cuestión importante: que una instancia participativa se politice o no, tendrá efectos muy diferentes. Justamente, esto nos permite leer y comprender los efectos de la institucionalización y regulación de la participación estudiantil en las escuelas por parte de la política educativa (normativas), o bien, de las gestiones directivas y de las pujas de los estudiantes por ampliar sus márgenes de actuación, o dicho en otros términos: por ampliar el margen de participación hacia la politización de sus demandas. Por último, nos posibilita problematizar los casos muy frecuentes en que, aún intentando "despolitizar" la escuela a partir del rechazo a las identidades partidarias, la "no politización” refiere a la eliminación de posibles fuentes de antagonismo y su reemplazo por otro tipo de proyectos participativos o pedagógicos.

Esto último nos permite visibilizar los casos de colonización o avasallamiento por parte de los adultos de los espacios de los jóvenes, tal como ejemplificáramos al comienzo. En la escuela, no hay una situación de igual- 
dad entre adultos y jóvenes: se trata de posiciones, de dispositivos y de sujetos que ellos constituyen con posiciones de poder diferencial. Lo político en la escuela puede normalizarse y también la escuela puede impedir su emergencia, y esto no es un juego de diferencias y disputas entre iguales, aunque siempre está abierto a la contestación y resistencia. Por ello, los dispositivos escolares posibilitan ambas cosas: la emergencia y la obturación de lo político. Esta perspectiva nos permite, por ende, analizar la política de los y las jóvenes en la escuela atendiendo no sólo a lo que los jóvenes "hacen" y "dicen hacer" sino a la compleja relación política entre jóvenes y adultos.

\section{La dimensión del gobierno escolar y lo político}

El recorrido hecho hasta aquí nos permitió explicitar cómo pensamos lo político en el espacio escolar. Sin embargo, se hace necesario también relacionarlo con la política en la escuela y para ello, un concepto de utilidad es el de gobierno escolar, que por supuesto es más allá de la tan mentada “gestión“. El gobierno escolar conforma las reglas de juego explícitas e implícitas que son capaces de generar ciertas condiciones para la participación, -y eventualmente la politización- a la vez que dichas estructuras son resultado de ella ${ }^{8}$. Recordemos que la política, el andamiaje institucional y sus reglas son producto de un modo contingente de resolución de lo político. Estamos frente a una doble dimensión: el gobierno escolar está constituido por lo político, a la vez que en su funcionamiento y despliegue posibilita u obtura su emergencia (posterior).

Más allá de que -como se mencionó- cualquier cuestión tiene la potencialidad de politizarse, lo cierto es que las normas, reglas y estructuras de autoridad vigentes en el sistema educativo en general, y en las escuelas en particular, delimitan quien puede tomar decisiones, sobre qué y cómo, y junto con ello, define qué legitimidad tienen las voces de los distintos actores. Es decir, delinean un determinado escenario para la emergencia de la conflictividad y lo político. En este punto vale aclarar que ello no se circunscribe solamente a las reglamentaciones y normas escritas sino también a las reglas informales, creencias tácitas y prácticas sedimentadas que conforman verdaderas culturas institucionales.

8 Nos referimos a que, como mencionamos párrafos arriba, determinadas estructuras también son producto y resultado de la cristalización y sedimentación de formas en que se ha resuelto lo político (Cfr. Retamozo Benítez, 2009). 
Hablar de gobierno escolar y no de gestión implica considerar que las escuelas, insertas en sistemas educativos, están atravesadas y son ellas mismas estructuras de poder. Así, el gobierno escolar está conformado por un conjunto de normas y reglas que estructuran la acción social, definen actores legítimos y establecen instrumentos y estructuras definidos para implementarlas (Gvirtz y Minvielle, 2009). El sistema educativo argentino, como muchos otros en América Latina, supone un modelo de decisión, administración y gestión fuertemente centralizados en el Estado y con un ordenamiento jerárquico entre sus distintas instancias. Si tenemos en cuenta la cantidad de cuestiones sobre las que se decide en el gobierno del sistema educativo, es fácil observar que la escuela como unidad tiene un margen de decisiones acotados sólo a algunas cuestiones, y dentro de estas, muchas tienen que ver con adaptar y concretizar decisiones tomadas por instancias superiores. Numerosos aspectos clave que hacen de la oferta educativa ${ }^{9}$ se definen de modo jerárquico y centralizado. Esto no significa que los directivos sean meros ejecutores, por el contrario, gran parte de las formas concretas que adoptan los procesos de transmisión cultural y los vínculos cotidianos están delineados por lo que pasa en la propia escuela y lo que "van haciendo" y decidiendo sus actores.

En síntesis, es posible sostener que si bien las escuelas tienen un conjunto importante de decisiones a su cargo en la gestión del día a día escolar, el modelo de gobierno escolar que prima es el jerárquico antes que el de participación democrática. Y dentro de esta jerarquía, los estudiantes son los que menos voz y participación legitimada tienen. Se desprende de lo anterior que entonces, puede haber muchas instancias participativas, e incluso docentes y estudiantes pueden entender que se hace política, a la vez que las decisiones sobre la escuela son tomadas por otros actores. Así, no es arriesgado interpretar que cuando la acción colectiva de los alumnos se politiza dentro de la escuela, tiene que ver no sólo con el reclamo por la obtención de distintos

9 Dentro de las decisiones a tomar por el gobierno de un sistema, podemos considerar tres tipos de decisiones. Las primeras, pueden englobarse como de índole académica y tienen que ver con: a) Definición del Curriculum, b) Organización de los métodos y materiales didácticos, c) Definición de las políticas de evaluación de los alumnos, d) Definición de las políticas de admisión, e) Asignación de la matrícula a las escuelas, f) Programación e implementación de proyectos pedagógicos especiales. Las segundas, de índole administrativo financiera tienen que ver con: a) Reclutamiento contratación y despido del personal, b) Evaluación del desempeño y capacitación del personal, c) Diseño de la estructura organizacional, d) Elaboración del presupuesto, e) Auditoría y control . Un tercer tipo de decisiones tienen que ver con el régimen de convivencia escolar, y ello abarca: a) la elaboración de un régimen o reglamentos de convivencia b) implementación de premios y sanciones. 
bienes -o reconocimientos- físicos o simbólicos, sino con una puja por ampliar sus márgenes de intervención en la toma de decisiones relevantes de la vida escolar en una institución bastante "cerrada" hacia ellos en términos de reconocimiento. Los estudiantes que logran politizar su acción colectiva, lo hacen a partir de un conjunto de necesidades o derechos que se construyen colectivamente. En algunos casos, irán más allá de la escuela y sus autoridades y deberán dirigirse a las instancias estatales y al espacio público societal.

De este modo, considerar a las escuelas no como meras organizaciones sino a partir de la micropolítica (Ball, 2002) implica entenderlas como espacios de disputa de poder, donde los diversos actores pugnan por el control, hay diversidad de objetivos e intereses y están ideológica y valorativamente orientados. En las formas concretas en las que se desarrollan estas micropolíticas a nivel de la institución escolar, re construyen las macropolíticas. Por esto mismo, tienen capacidad de "crear" normas propias y entonces de promover u obturar determinados espacios participativos (o de imprimirles un formato, marcarle límites). En resumen, las reglas y "climas" escolares parecen generar diferentes condiciones para la irrupción de lo político en el espacio escolar. Esto contribuye a explicar por qué hay tantas diferencias -en cuanto a la presencia y modalidad de organizaciones estudiantiles y posibilidades de politización- entre diferentes escuelas. Muchas escuelas tienen realmente culturas institucionales reacias a la participación y a la politización de los estudiantes (y son exitosas en eso), mientras que para otras, esto es un valor agregado y los estudiantes o sus padres las eligen por eso. A la vez, la conceptualización de gobierno escolar, estructuras de autoridad y toma de decisiones nos remite nuevamente a la distinción entre la política y lo político y su expresión en las instituciones: justamente lo político se conforma como tal donde un colectivo es capaz de reclamar y disputar un lugar en ese gobierno escolar, en "ampliar el campo de lo posible" en términos de quiénes y cómo toman decisiones que los afectan a todos a partir de un ser nosotros.

\section{La escolarización de la política o la domesticación de lo político en la escuela}

En la presentación de este trabajo, dijimos que lo político en el espacio escolar -retomando una perspectiva foucaultiana- puede ser normalizado. Cuando hablamos de lo político y la política en el espacio escolar estamos 
hablando de una emergencia que no se da en un campo institucional cualquiera, sino en unos dispositivos específicos que producen determinados efectos sobre aquello que le es ajeno y en efecto, la política es leída por la institución escolar como "ajenidad". Esto se vincula con una configuración histórica particular de la escuela, parafraseando a Dubet (2004) como un intento de la institución escolar de preservar "los muros del santuario".

En tanto concepto genealógico, el dispositivo presupone en el mismo momento, la operación de un poder y la producción de saber. Un dispositivo escolar es producto de la institución escolar y combina de un modo particular prácticas discursivas y no discursivas produciendo determinados efectos de saber-poder. En síntesis, podemos retomar la propuesta de Dussel (2006, p. 90) de pensar este concepto como una combinación particular de elementos en su configuración simultánea de saberes, sujetos y tecnologías. Si observamos atentamente las actividades y formas participativas que describíamos anteriormente, hemos constatado que a lo largo de 30 años en Argentina -y más allá-, vemos que estas se reiteran, permanecen, se reinventan. Todas son reconocibles y tienen sus orígenes en la escuela secundaria. ¿Por qué insistimos con ellas? Porque es posible concluir que estas son capaces de permitir la entrada de la política en la escuela pero bajo sus propias reglas, bajo su órbita y espacio, bajo aquellas cosas que pueden constituirse como "de interés" - permitido- de los estudiantes. Es decir, la política puede entrar así de modo legítimo desdibujando, suavizando, cambiando las formas propias de la práctica política de -por ejemplo- la militancia partidaria. La mayor evidencia en este sentido es la "utilización" y la pugna por la orientación de estas actividades por parte de los estudiantes que sí son participantes activos: mientras algunos buscan conservar su carácter neutral y cooperativo de estas actividades, otros saben que deben "aprovecharlas" para "meter el debate político" en la escuela, o bien, para reclamar en el espacio público más amplio. Son utilizadas y direccionadas también por directivos, por supervisores y otras instancias del sistema educativo.

Queremos decir, entonces, que estos dispositivos habilitan la posibilidad de politizar y de despolitizar la cuestión estudiantil en el ámbito escolar bajo sus propias reglas. Por otra parte, es posible arriesgar que la estabilidad y regularidad de dichas prácticas a lo largo del tiempo y en diferentes escuelas, no son simplemente el resultado directo de cambios en las normativas educativas. Más bien, parecen ser prácticas estabilizadas que resultan de la combinación de diversos cambios, préstamos, recontextualizaciones en di- 
ferentes niveles: del sistema educativo, de las escuelas, de las culturas juveniles, del mundo de las prácticas políticas de las juventudes que han ido influenciándose mutuamente.

Cabe reiterar que aquí proponemos una hipótesis a partir no sólo de nuestros propios hallazgos, sino de ciertos rasgos clave que hemos visibilizado en los estudios historiográficos sobre el tema (Larrondo, 2014). Las instancias de participación en la escuela secundaria no son iniciativas recientes en el sistema educativo. Tomando el caso argentino, vemos que a partir de los clubes colegiales de la década de 1940 (Cammarota, 2014), o en la Unión de Estudiantes Secundarios en el primer peronismo (Manzano, 2009), los jóvenes fueron utilizando estos espacios vinculados al obrar en común y la identidad estudiantil de diferentes maneras, donde no estuvo exenta la vocación de "expresión" de sus ideas políticas y su cosmovisión en tanto jóvenes. Distintos grupos políticos utilizaron estos formatos y actividades "propias de los estudiantes secundarios" a la vez que es posible suponer que hayan contribuido a promoverlas y conformarlas. Por ejemplo, en los tempranos setentas la Federación Juvenil Comunista organizaba campamentos escolares, de igual modo, las escuelas católicas y los grupos juveniles vinculados al cristianismo de base emprendían campañas o campamentos solidarios también en el ámbito de las escuelas secundarias.

El "operativo Güemes" implementado por la UES de 1974 era una acción específica para y por estudiantes secundarios (Manzano, 2009). Estas prácticas, posiblemente con distintos orígenes, han permeado la escuela y se han establecido allí; a la vez que es posible pensar que también la escuela, al legitimarlas, ha podido "prestar" estas iniciativas a las organizaciones juveniles. El Estado también utilizó estratégicamente estos dispositivos de participación estudiantil-escolar: la propia dictadura militar de 1976 convocó a los secundarios al operativo "Marchemos a las fronteras" (Lvovich, 2009); mientras que en el retorno democrático la normativa alfonsinista buscaba que las asociaciones estudiantiles tuvieran un carácter cooperativo y cultural y se educara allí en las prácticas democráticas. Por otra parte, fuera de la escuela, las organizaciones políticas retoman las actividades solidarias y recreativas como propias de la militancia secundaria, lo cual permite dar un lugar y un conjunto de tareas a los militantes adolescentes. Ahora bien, no estamos diciendo que todas estas instancias y actores sean equivalentes.

Lo que intentamos mostrar y resulta central es que todas ellas implican un conjunto de actividades que tienen como eje la escuela secundaria y la 
condición estudiantil; sus regularidades dan muestra de una configuración de prácticas identificables como "intrínsecas" a la condición de ser estudiante secundario. Así, fueron conformando un dispositivo de participación juvenil en su interior. Esto es un hallazgo que emerge como una hipótesis muy fuerte para comprender el vínculo entre política y escuela. En otras palabras: el análisis histórico de las formas en que los y las jóvenes han participado en las escuelas, nos ha llevado a plantear que se evidencia una "escolarización de la política". Esto es un particular proceso por el cual la institución escolar habilita (y ha habilitado) la participación y/o la emergencia de lo político en su interior a la vez que permite cierto control de la conflictividad. Este "dispositivo" es resultado de interacción entre ciertas cualidades y procesos propios del sistema educativo, otras instancias sociales y la acción de los jóvenes. La apuesta de entender la política en la escuela media a partir de la categoría de escolarización de la política, surge a la luz de analizar la institución escolar como un sistema que no es sólo reproductivo, sino productivo (Gvirtz, 1999). Los conceptos de "gramática escolar" (Tyack y Cuban, 2001) y "cultura escolar" (Viñao, 2002) ${ }^{10}-\mathrm{y}$ los estudios sobre los que ellos se fundamentan-, sostienen que los sistemas educativos tienen la capacidad para reinterpretar y adaptar "el afuera" a su entorno.

Por otra parte, una importante tradición de estudios del curriculum se ha encargado de mostrar que la escuela es un ámbito de producción de saberes y no sólo de reproducción. En otras palabras, "los contenidos de la educación son, en gran medida construcciones escolares específicas y, por lo tanto; la escuela no se reduce a un ámbito de reproducción de la cultura (que se produce fuera de ella) sino que se establece como un ámbito de práctica social diferente, con reglas y productos que le son propios" (Gvirtz, Larripa y Oria, $2006 \mathrm{~s} / \mathrm{p})$.

Dentro del campo de la historia del curriculum, diversos trabajos han mostrado procesos de creación de disciplinas desde la propia escuela, tal es el caso de la gramática o la geografía (Chervel, 1991; Goodson y Dowbigging, 1990; citados en Gvirtz, 1999). Otros dispositivos han mostrado su capacidad de producir efectos, inclusive, influenciando y modificando as-

10 Dicho autor sostiene que las escuelas, en tanto sistemas, están constituidas por "un conjunto de teorías, ideas, principios, normas, pautas, rituales, inercias, hábitos y prácticas (formas de hacer y pensar, mentalidades y comportamientos) sedimentadas a lo largo del tiempo en forma de tradiciones, regularidades, y reglas de juego no puestas en entredicho y compartidas por sus actores, en el seno de las instituciones educativas" (Viñao, 2002, p. 73). 
pectos culturales de la sociedad en general: por ejemplo, los rituales escolares como constructores de significados sobre la nacionalidad (Amuchástegui, 2002); o la influencia de los libros de texto escolar en torno a los imaginarios colectivos sobre la historia nacional y el territorio (Romero y De Privitiello, 2004). Sostenemos que la escuela, al tener que cumplir con su función de administrar y distribuir saberes - pero también regulaciones morales- produce discursos y prácticas específicas a través de dispositivos escolares: cuadernos de clase, libros de texto, rituales. En tanto productos escolares, se trata de establecer "cómo y de qué manera [saberes externos a la escuela] se articulan en su trama, tal vez desdibujando la propia, pero generando algo distinto, otro discurso, el escolar" (Gvirtz, 1999, p. 22) Así, los hallazgos de nuestro trabajo, parecen mostrar la presencia de dispositivos ${ }^{11}$ que buscan "administrar" la participación de los jóvenes y la política de un modo particular, produciendo una forma escolar de hacer política, una política "escolarizada".

La segunda evidencia que consideramos para sostener el proceso de escolarización de la política refiere al cómo las identidades militantes -allí cuando existen- se hacen presentes en la escuela a través de un proceso de "adaptación obligatoria" 12 al espacio escolar. Esta regularidad también nos muestra la presencia de un dispositivo de escolarización de la política. Para poder entrar en la escuela, demandas, marcos e identidades político partidarias tienen que adquirir un carácter escolar. Diremos que las identidades políticas tienen que perder algo, deben transformarse y presentarse como identidades estudiantiles legítimas. En definitiva, la escuela media parece tener -aún en la diversidad de cada caso- mecanismos de "admisión" para la política: opera rechazando ciertos modos de hacer política, aceptando otros, re direccionándolos e intentando controlar el desarrollo de la conflictividad y

11 En la teoría foucaultiana, un dispositivo es un es un conjunto de prácticas discursivas y no discursivas (Castro, 2004). Puede ser entendido como "una red de relaciones que se pueden establecer entre elementos heterogéneos: discursos, instituciones, arquitectura, reglamentos, leyes, medidas administrativas, enunciados científicos, proposiciones filosóficas, morales, filantrópicas, lo dicho y lo no dicho. (...) El dispositivo establece la naturaleza del nexo que puede existir entre esos elementos heterogéneos. Asimismo, el dispositivo tiene una función de responder a una urgencia, tiene una función estratégica en un conjunto social" (Castro, 2004, p. 98).

12 En la Argentina -como en la mayoría de los países de la región-, la expresión de identidades político partidarias dentro de la escuela son consideradas proselitismo político y están prohibidas por las normativas oficiales. Ninguna agrupación estudiantil puede presentarse como perteneciente a un partido político o ideologías política definida. 
el resguardo su carácter -“"neutral” y no partidario. En definitiva, retomando nuestra conceptualización anterior, lo político no se constituye en la escuela de modo automático aunque haya instancias participativas. Aún en las escuelas con "tradición militante", la institución siempre intenta operar traducciones sobre ello. Este "mantener bajo control", puede ceder ante ciertos acontecimientos y emergencias, resultado de un campo de fuerzas.

Como mencionamos, es claro que además de estas actividades, tienen lugar eventualmente acciones colectivas vinculadas directamente al reclamo y a la protesta contenciosa. Este conjunto de acciones suelen presentar -cuando emergen- mayores niveles de conflictividad; y justamente muchas veces son rechazadas porque subvierten el carácter escolar. No obstante, hay que tener en cuenta que las acciones reivindicativas suelen combinarse con otras acciones: la construcción de una acción colectiva confrontativa conlleva formas de organización y solidaridad previas vinculadas a estas actividades participativas "cooperativas" de las que hablamos al principio. Además, parte de los grupos que son capaces de politizar la escuela obtienen legitimidad y reconocimiento a través de ellas; de su organización exitosa. Es por eso que -para decirlo en términos simples- aún los estudiantes militantes más "combativos" participan y organizan aquellas actividades que fuera de la escuela consideran de modo crítico como "lavadas de contenido político" o "actividades menores".

La política escolarizada suele entrar en tensión con aquellos debates, propuestas, identidades y objetivos tanto referidos a la protesta, como a los marcos provenientes de las organizaciones políticas externas a ellas. La escuela es como un tamiz que permite que sucedan unas formas de la acción y no otras, que "entren", a la vez que no puede eliminar del todo las identidades políticas más amplias ni la conflictividad. Al respecto, resulta interesante observar los contenidos de los afiches de campaña y ciertas actividades de los centros de estudiantes. En ellos se observa que, más allá de la presencia de militantes en las organizaciones, su discurso público recoge iniciativas participativas, propuestas muy similares entre sí: colectas, arreglo de las escuelas, charlas, actividades culturales, festivales, fiestas y torneos, entre otros. Los símbolos de identidades partidarias se utilizan de un modo indirecto y entrelazado con las cuestiones participativas escolares. Las propuestas "escolares" permiten en cierto modo, neutralizar aquella referencia explícita que la escuela no acepta. Por fuera de la escuela, pero no alejados de ella, el movimiento estudiantil conformado en organizaciones de segun- 
do grado y partidos o movimientos sociales, pugna para que "la política con mayúscula" entre en la escuela. Pero sabe utilizar sus códigos: genera e impulsa propuestas posibles de ser desarrolladas en su interior.

Si bien estas dinámicas fueron observadas en escuelas de Argentina, creemos que los procesos generales a los que remiten pueden ser observables -con sus variaciones- en distintos sistemas educativos, ya que estamos hablando de dos lógicas estructurales: la del campo político y la de la escuela como institución moderna.

\section{Reflexiones finales}

En este recorrido, hemos querido proponer una clave de lectura sobre la participación de los jóvenes en la escuela la cual enfatiza un doble carácter: su potencialidad política (y no solo participativa) y además escolar. Frente a la presencia de múltiples formas de expresión política de los y las jóvenes y de la concomitante diversidad de prácticas, creemos que, no obstante, es necesario tomar recaudos y no renunciar al análisis de la acción que siempre comporta un grado de exterioridad y la posibilidad de hacer distinciones. Es decir, podemos encontrar participación en la escuela sin política, y también podemos encontrar acción política en la escuela y saliendo de ella, pero siempre se trata de una política escolarizada. La escolarización de la política es un proceso, un efecto producido por dispositivos escolares que tiene como resultado la posibilidad de emergencia de lo político en el espacio escolar (a partir de determinadas características y condiciones) pero también puede habilitar su obstaculización u obturación. En ocasiones, los límites entre estas cuestiones son muy difusos. Esto surge del estudio y la consideración sobre la centralidad de la institución escolar. En este sentido, analizar una práctica política juvenil dentro de la escuela debe llevarnos a tomar al dispositivo escolar como central en la teorización y -posteriormente- en la observación. Por otro lado, $-\mathrm{y}$ esto no ha sido objeto de reflexión en este trabajo en particular dado que nos hemos centrado en lo escolar- la acción estudiantil es capaz de politizarse y "salir" de la escuela a partir de la protesta dirigida al sistema educativo y al estado, en la conformación de movimiento estudiantil o "movidas" (Aguilera, 2016) estudiantiles. Desde ya, esta dinámica modifica, afecta y es afectada por aquello que sucede en la escuela y en ocasiones son inseparables. 
Creemos que la conceptualización presentada puede resultar iluminadora para la investigación empírica, para hacer visibles determinadas cuestiones. Sin embargo, más allá de esto, pensamos que es interesante enfatizar algunas consecuencias para la acción política de los y las jóvenes que de ella se desprenden. Si como hemos propuesto en este trabajo - a modo de hipótesis interpretativa- la escuela a partir de sus dispositivos específicos ha contribuido a conformar una forma "escolarizada" de la política; resulta interesante plantear algunas cuestiones en torno a sus implicancias. Estas deben leerse contextualizadas en otra fuerte persistencia: la incompleta inclusión de la voz estudiantil en las estructuras de decisión del gobierno escolar en todos sus niveles. Si bien las normativas han avanzado en la ampliación de las instancias de organización y participación de los estudiantes secundarios en el marco escolar, y además lo ha planteado en términos de derechos, parece haber un límite. Este tiene que ver con la potestad para la toma de decisiones. Es cierto que el sistema educativo es fuertemente jerarquizado, pero aún los directivos y docentes tienen injerencia en diversidad de aspectos institucionales; y por otro lado, tienen representación gremial reconocida. Estos datos "obvios" nos permiten contrastar la situación y el rol adjudicado a los estudiantes. Los y las estudiantes (de Argentina, pero también lo hemos visto en otros países de la región) tienen voz y posibilidad de participar en la toma de decisiones de modo legítimo sólo en márgenes muy limitados. En definitiva: las organizaciones estudiantiles escolares pueden ser un espacio de participación, expresión y representación de intereses, aunque la posibilidad de intervenir legítimamente en aspectos institucionales -tanto de la escuela como de otras instancias del sistema educativo- permanece reducida. De este modo, la conflictividad parece ser casi el único camino para ser escuchados frente a demandas de importancia.

Por otra parte, el reconocimiento de la diversidad de formatos de participación al interior de las escuelas muestra que la participación implica o puede implicar cosas muy diferentes. Así, la gran diversidad de tipos de organizaciones escolares, -como así también sus objetivos- puede redundar en un desplazamiento del rol de representación y construcción de intereses comunes y por ende, dificultades para la politización. Cuando esto último no puede constituirse, los estudiantes no pueden inscribirse como sujetos de derechos: esa es la cuestión que creemos, está detrás de la importancia de distinguir entre "participación" y "política escolar". Por último, mientras que el sistema educativo ha promovido dar una mayor importancia a la ex- 
presión de los alumnos y lentamente ha avanzado en la inclusión de las culturas juveniles, las identidades político partidariasdu s(que constituyen, para muchos jóvenes, un lazo de fundamental importancia con sus herencias familiares, grupos de pares, ideologías) deben permanecer fuera de la escuela, dado que las normativas continúan estableciéndolas como contaminantes, externas, tabú. Así, en los efectivos avances por el reconocimiento de la voz de los jóvenes en las escuelas, también aparecen fuertes contradicciones.

En definitiva: en los límites entre lo participativo y lo político, lo local y lo universal, las demandas y necesidades y el lenguaje de derechos se juega -a nuestro entender- el hecho de que los y las jóvenes estudiantes tengan más o menos posibilidades de acceder a las herramientas que les permiten conformar organizaciones, apelar al lenguaje de derechos y eventualmente, defenderlos y ampliarlos. Una cuestión en la que tanto las instituciones políticas y las educativas tienen fuerte injerencia y responsabilidad directa y también en interacción cotidiana con las nuevas generaciones.

\section{Bibliografía}

Annunziatta, R.(2012). “Resignificar la participación”. En Revista de Ciencias Sociales, UBA «https://www.academia.edu/3113257/Resignificar_la_participa ci\%C3\%B3n> [12-12-2016].

Aguilera, O. (2016). Movidas, movilizaciones y movimientos. Culturas políticas y políticas de las culturas juveniles en el Chile de hoy. Santiago de Chile: RIL Editores.

Amuchástegui, M. (2002). Los actos escolares con bandera. Genealogía de un ritual. Tesis de Maestría en Educación. Buenos Aires: Escuela de Educación, Universidad de San Andrés.

Ball, S. (2002). La micropolítica de la escuela. Barcelona: Paidós.Bernstein, B. (2001). Clases, códigos y control. La estructura del discurso pedagógico, 4. Madrid: Morata.

Bonvillani, A., Palermo, A., Vázquez, M., Vommaro, P. (2008). Juventud y política en la Argentina (1968-2008). Hacia la construcción de un estado del arte. Revista Argentina de Sociología, 6(11). Buenos Aires.

Cammarotta, A. (2014). Somos bachiyeres. Juventud, docencia y política en la cultura escolar del Colegio Nacional Mixto de Morón (1949-1969). Buenos Aires: Biblos. 
Castro, E. (2004). El vocabulario de Michel Foucault: un recorrido alfabético por sus temas, conceptos y autores. Buenos Aires: Prometeo/UNQui.

Chervel, A. (1991). Historia de las disciplinas escolares. Reflexiones sobre un campo de investigación. Revista de Educación, 295. Madrid: Ministerio de Educación Ciencia y Técnica.

Dubet, F. (2004). ¿Mutaciones institucionales y/o neoliberalismo? En: Emilio Tenti (Org.), Gobernabilidad de los sistemas educativos en América Latina. Buenos Aires: IIPE-UNESCO.

Dussel, I. (2006). De la primaria a la EGB: ¿Qué cambió en la enseñanza elemental en los últimos años? En: F. Terigi (Comp.), Diez miradas sobre la escuela primaria. Buenos Aires: Fondo de Cultura Económica.

Enrique, I. (2011). La participación estudiantil en la escuela secundaria en la Argentina. Reconstrucción del conflicto en torno al protagonismo político de los jóvenes. Tesis de Maestría en Políticas Sociales. Buenos Aires: Facultad de Ciencias Sociales, Universidad de Buenos Aires.

Goodson, I. y Dowbiggin, I. (1990). Cuerpos dóciles. En: Stephen Ball (Comp.), Foucault y la educación. Disciplinas y saber. Madrid: Morata.

Gvirtz, S. (1999). El discurso escolar a través de los cuadernos de clase. Buenos Aires: Eudeba.

Gvirtz, S., Larripa, S., Oría, Á. (2006). Prácticas discursivas pedagógicas, didácticas y escolares: Algunas categorías para repensar la relación entre el saber y la escuela. Documento no publicado del Observatorio Latinoamericano de Políticas Educativas.

Gvirtz, S. y Minvielle, L. (2009). Participation of Civil Society in School Governance: Comparative Research of Institutional Designs in Nicaragua and Brazil. En: Inequality in Education. CERC Studies in Comparative Education, 24.

Krauskopf, D. (1998). Dimensiones críticas en la participación social de las Juventudes. En: Sergio Balardini (Comp.), La participación social y política de los jóvenes en el horizonte del nuevo siglo. Buenos Aires: CLACSO.

Larrondo, M. (2014). Después de la Noche. Participación en la escuela y movimiento estudiantil secundario: Provincia de Buenos Aires, 1983-2013. Tesis de Doctorado. Los Polvorines: Universidad Nacional de General Sarmiento-IDES

Lechner, N. (2000). Nuevas Ciudadanías. Revista de Estudios Sociales, 5, 25-31. Bogotá: Universidad de Los Andes. 〈http://res.uniandes.edu.co/view. php/110/> [12-12-2016]. 
Lvovich, D. (2009). Estrategias movilizadoras del régimen militar destinadas a sectores juveniles e infantiles. Ponencia presentada en XII Jornadas Interescuelas/ Departamentos de Historia: Bariloche.

Manzano, V. (2009). The making of Youth in Argentina: Culture, politics and sexuality. 1956-1976. Tesis doctoral. Indiana University.

Marchart, Olivier (2009). El pensamiento político posfundacional. La diferencia política en Nancy, Lefort, Badiou y Laclau. Buenos Aires: Fondo de Cultura Económica.

Merklen, D. (2005). Pobres ciudadanos. Las clases populares en la era democrática (Argentina 1983-2003). Buenos Aires: Gorla.

Mouffe, Ch. (2008). El retorno de lo político. Comunidad, ciudadanía, pluralismo, democracia radical. Barcelona: Paidós.

Núñez, P. (2013). La política en la escuela. Buenos Aires: La Crujía.

Perrenoud, Ph. (2006). El oficio de alumno y el sentido del trabajo escolar. Madrid: Ed. Popular.

Retamozo Benítez, M. (2009). Lo político y la política: los sujetos políticos, conformación y disputa por el orden social. Revista Mexicana de Ciencias Políticas y Sociales, LI 206, mayo-agosto. Universidad Nacional Autónoma de México.

Romero, L. A. y De Privitellio, L. (2004). La Argentina en la Escuela. La idea de Nación en los textos escolares. Buenos Aires: Siglo veintiuno.

Rosanvallón, P. (2008). La contrademocracia. La política en la era de la desconfianza. Buenos Aires: Manantial.

Tyack, D. y Cuban, L. (2001). En busca de la utopía. Un siglo de reformas en las escuelas públicas. México: Fondo de Cultura Económica.

Vázquez, M. (2015). Juventudes, políticas públicas y participación Un estudio de las producciones socioestatales de juventud en la Argentina reciente. Buenos Aires: Ediciones del Aula Taller.

Viñao, A. (2002). Sistemas educativos, culturas escolares y reformas. Continuidades y cambios. Madrid: Morata.

Fecha de recepción: 19/12/2016; fecha de aceptación: 30/05/2017;

fecha de publicación: 30/06/2017 